\title{
Pigmented basal cell carcinoma of the eyelid in Hispanics
}

\author{
Lily Koo Lin' \\ Han Lee ${ }^{2}$ \\ Eli Chang'
}

'Department of Oculoplastics, Doheny Eye Institute, Los Angeles, CA, USA; ' Department of Dermatology,

Keck School of Medicine

of the University of Southern

California, Los Angeles, CA, USA
Correspondence: Eli Chang

Doheny Eye Institute, I 450 San Pablo

Street DEl 4705, Los Angeles, CA 90033 ,

USA

$\mathrm{Tel}+\mathrm{I}$ 323-442-6405

Email oculoplastics@doheny.org
Background: Pigmented basal cell carcinoma (PBCC) of the eyelid has not been well cited in the literature, and is often overlooked in the differential diagnosis of pigmented eyelid lesions. We aim to describe PBCC of the eyelid in Hispanic patients.

Methods: Retrospective review of patients with eyelid skin cancer who presented to the Department of Dermatology at the Keck School of Medicine of the University of Southern California and the Doheny Eye Institute from January 2002 to November 2005.

Results: Sixty-nine of the 79 patients with eyelid skin cancer had basal cell carcinoma. Eight of these patients were Hispanic. Four of the eight Hispanic patients had PBCC.

Conclusions: Although eyelid PBCC is regarded as a rare condition, it may occur more commonly in the Hispanic population and should be remembered in the differential diagnosis of pigmented eyelid lesions.

Keywords: pigmented basal cell carcinoma, eyelid, skin cancer, lesions

Although pigmented basal cell carcinoma (PBCC) in individuals with darker skin color has been well described in dermatologic literature, it is recognized as a rare condition in the general population, and has rarely been reported specifically to the eyelid region (Duke-Elder and MacFaul 1974; Charles 1975). Since PBCC is not commonly considered in the differential diagnosis by general ophthalmologists for eyelid lesions, it is often mistaken for melanoma (Scotto et al 1983). Indeed, some features of PBCC lesions, such as its irregular borders and dark pigment, are suggestive of melanoma (Pathak et al 1982). Reports of frequency vary. The frequency for all sites ranges from $1.1 \%$ to $8 \%$ (Bart and Schnall 1973). In one series that investigated the eyelid site only, $9 \%$ of all diagnosed basal cell carcinomas in a population of white patients were found to be PBCC (Hornblass and Stefano 1981).

Although Hispanic patients get skin cancer significantly less frequently than nonHispanic individuals (Pathak et al 1982; Harris et al 2001), PBCC of all sites has been shown to occur more frequently in Hispanics than in non-Hispanics (Bigler et al 1996). We have seen PBCC of the eyelid occurring with common frequency in our Hispanic patients. Our case series describes four of eight Hispanic patients who presented with primary eyelid malignant lesions that were proven on biopsy to be PBCC.

\section{Materials and methods}

Clinical medical records for patients seen between January 2002 and November 2005 by the Mohs surgery division of the Department of Dermatology at the Keck School of Medicine of the University of Southern California were reviewed retrospectively. Seventy-nine consecutive cases of primary eyelid skin cancer were found. Cases of eyelid basal cell carcinoma in patients of Hispanic descent were identified and studied. Hispanic descent was determined by heritage documentation based on questions asked 
of every patient admitted for Mohs surgery. The records were reviewed for patient history, presentation, lesion size, number of Mohs stages for excision, and defect size. The clinical records of these same patients from the Department of Oculoplastics and Reconstructive Surgery at Doheny Eye Institute were also reviewed. The records were reviewed for patient history, presentation, lesion duration and appearance, type of closure needed for reconstruction, and recurrence. No patient had previous treatment or biopsies prior to Mohs excision. The histopathological slides were read at the time of Mohs excision by the dermatopathologist. The study protocol was approved by the University of Southern California Institutional Review Board.

\section{Results}

Sixty-nine of 79 eyelid skin cancer cases were found to have basal cell carcinoma. Of these 69 patients, 8 were of Hispanic descent. Four of these patients had PBCC. Representative clinical photographs are seen in Figure 1 (Case 1) and Figure 2 (Case 4). All four patients were male, with a mean age of 63 years (range 57 to 75 years). Lesion duration ranged from 7 months to 6 years. None of these patients had lymphadenopathy. Two patients felt the lesion was secondary to minor trauma. All patients were treated with Mohs excision. No patient has experienced recurrence. There were no cases of neural or perineural involvement. Table 1 summarizes the findings for all four patients.

\section{Discussion}

A 2001 report (Harris et al 2001) on trends in the incidence of nonmelanoma skin cancers in southeastern Arizona found

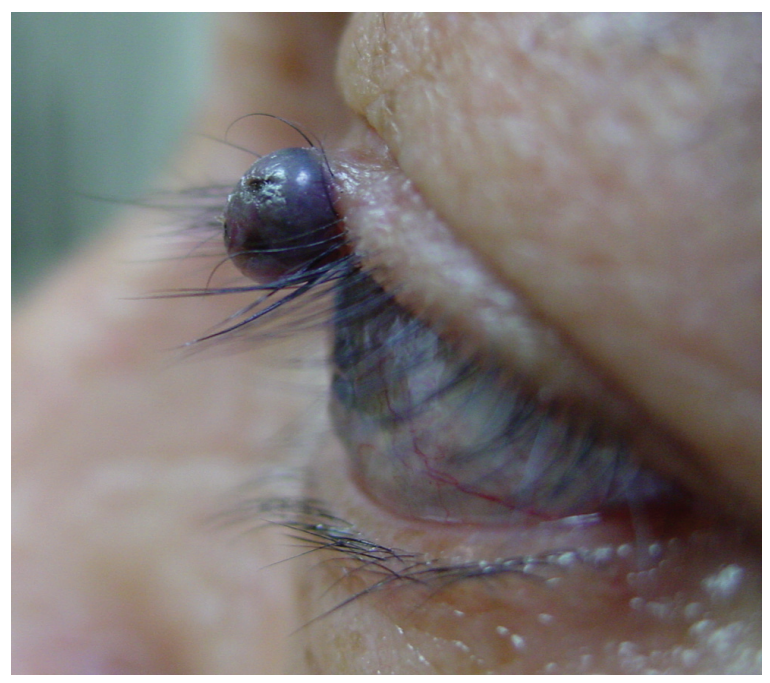

Figure I Darkly pigmented well -circumscribed, spherical, peduculated nodule of left upper lid.

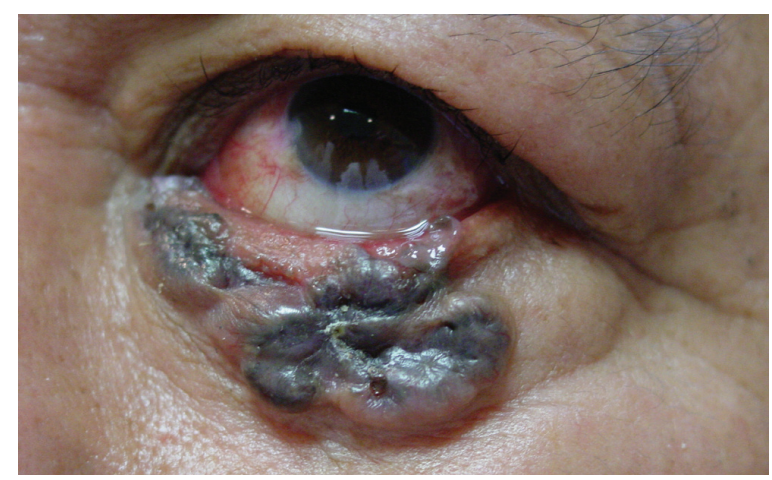

Figure 2 Pigmented, raised lesion encompassing right lower lid with areas of ulceration and madarosis, infiltrating the lid margin.

that non-Hispanic whites were 11 times more likely than Hispanics to develop either basal or squamous cell carcinoma. Similarly, a 1982 report on the incidence of basal cell carcinoma and melanoma in New Mexico found that these cancers occurred seven times less often in Hispanics than in non-Hispanics (Pathak et al 1982).

Although both basal and squamous cell carcinoma, as well as melanoma, occur with less frequency in the Hispanic population than in the non-Hispanic population, it has been shown that PBCC occurs more often in Hispanics. In one prospective series (Bigler et al 1996), for BCC at any site, $66 \%$ of all BCCs in Hispanics were found to be PBCC, whereas only $11 \%$ of all BCCs in non-Hispanic patients were PBCC. Pigmented basal cell carcinoma has also been shown to occur with higher frequency in patients with darker skin color (Smith et al 1960; Kalter et al 1984; Abreo and Sanusi 1991).

Histologic studies have shown that the pigment in PBCC originates from the surrounding skin (Bleehan 1975).

Hornblass and Stefano (1981) described pigmented basal cell carcinoma specific to the eyelid in white patients. Haye and Dufier (1976) reported a relative frequency of 1\% for PBCC of the eyelid in the population in Paris, which increased to $45 \%$ in Mediterranean ethnic groups. After careful review of the literature, to the best of the authors' knowledge, eyelid PBCC specific to the Hispanic population has not been reported. Just as eyelid PBCC is more frequent in the darker skinned Mediterranean population, it is likely that PBCC of the eyelid also occurs more commonly in Hispanics than in non-Hispanics.

Because PBCC is not commonly considered in the differential of eyelid pigmented lesions of general ophthalmologists, these lesions are often misdiagnosed as melanoma. Both lesions can have irregular borders and dark pigment. However, some features of PBCC can help differentiate it from 
Table I Characteristics of Hispanic patients with eyelid pigmented basal cell carcinoma

\begin{tabular}{|c|c|c|c|c|c|c|c|c|c|c|c|}
\hline Case & Sex/age & Location & Duration & Bleeding & Ulceration & Madarosis & $\begin{array}{l}\text { Initial size } \\
(\mathrm{cm})\end{array}$ & $\begin{array}{l}\text { Number of } \\
\text { mohs stages } \\
\text { needed }\end{array}$ & $\begin{array}{l}\text { Defect } \\
\text { size }(\mathrm{cm})\end{array}$ & $\begin{array}{l}\text { Type of } \\
\text { closure }\end{array}$ & $\begin{array}{l}\text { Follow } \\
\text { up }\end{array}$ \\
\hline I & $M / 57$ & Left upper lid & 2 yrs & No & No & No & $0.5 \times 0.4$ & 1 & $0.5 \times 0.7$ & $\begin{array}{l}\text { Second } \\
\text { intention }\end{array}$ & $2 \mathrm{yrs}$ \\
\hline 2 & $M / 75$ & Right lower lid & $7 \mathrm{mos}$ & Yes & Yes & Yes & $1.2 \times 1.0$ & 2 & $2.2 \times 2.0$ & Hughes & $2 \mathrm{yrs}$ \\
\hline 3 & $M / 57$ & Left lower lid & 6 years & No & No & No & $4.2 \times 2.0$ & 2 & $5.0 \times 3.0$ & Hughes & $\mathrm{I} y r$ \\
\hline 4 & $M / 63$ & $\begin{array}{l}\text { Left medial } \\
\text { canthus }\end{array}$ & 3 yrs & Yes & Yes & Yes & $1.0 \times 0.8$ & 2 & $2.5 \times 2.0$ & Hughes & $7 \mathrm{mos}$ \\
\hline
\end{tabular}

melanoma. Pigmented basal cell carcinoma is more likely to have mottled appearance since the pigment is often located superficially in the dermis (Bigler et al 1996). Melanoma, on the other hand, tends to have intense or masking pigment (Haye and Dufier 1976). Other features that help differentiate PBCC from melanoma include a translucent or pearly sheen, firm or indurated lesions, areas of ulceration, and raised edges (Hornblass and Stefano 1981; Bigler et al 1996).

Clinicians should be aware that PBCC of the eyelid occurs more frequently in Hispanics, a population less frequently affected by other skin carcinomas, and consider $\mathrm{PBCC}$ on their differential diagnosis of all pigmented eyelid lesions.

\section{Disclosure}

The authors received no financial support nor do they have any proprietary or conflicting interests in the materials discussed in this manuscript.

\section{References}

Abreo F, Sanusi ID. 1991. Basal cell carcinoma in North American blacks. Clinical and histopathologic study of 26 patients. J Am Acad Dermatol, 25:1005-11.
Bart RS, Schnall S. 1973. Eye color in darkly pigmented basal cell carcinomas and malignant melanomas. An aid in their clinical differentiation. Arch Dermatol, 107:206-7.

Bigler C, Feldman J, Hall E, et al. 1996. Pigmented basal cell carcinoma in Hispanics. J Am Acad Dermatol, 34:751-2.

Bleehan SS. 1975. Pigmented basal cell epithelioma. Light and electron microscopeicc studies on tumours and cell cultures. Br J Dermatol, 93:361-70.

Charles NC. 1975. Basal cell carcinomas of the eyelids: pitfalls in diagnosis and therapy. J Dermatol Surg, 1:28-32.

Duke-Elder S, MacFaul PA. 1974. Carcinoma (epithelioma). In: System of Ophthalmology. Vol 13, Part I. The Ocular Adnexa, Diseases of the Eyelids. St. Louis: CV Mosby Co., pp. 420-42.

Harris RB, Griffith K, Moon TE. 2001. Trends in incidence of nonmelanoma skin cancers in southeastern Arizona, 1985-1996. J Am Acad Dermatol, 45:528-36.

Haye C, Dufier JL. 1976. Pigmented epitheliomas of the eyelids [in French]. Arch Ophtalmol (Paris), 36:633-44.

Hornblass A, Stefano JA. 1981. Pigmented basal cell carcinoma of the eyelids. Am J Ophthalmol, 92:193-7.

Kalter DC, Goldberg LH, Rosen T. 1984. Darkly pigmented lesions in darkskinned patients. J Dermatol Surg Oncol, 10:876-81.

Pathak DR, Samet JM, Howard CA, et al. 1982. Malignant melanoma of the skin in New Mexico 1969-1977. Cancer, 50:1440-6.

Scotto J, Fears, TR, Fraumeni JF. 1983. Incidence of nonmelanoma skin cancer in the United States. NIH Publication 83-2433.Bethesda, MD: US Dept. of Health and Human Services, National Institutes of Health; NIH Publication 83-2433.

Smith LM, Garrett HD, Hart MS. 1960. Pigmented basal- cell epithelioma: a comparison of its incidence and characteristics in the Latin-American and Anglo-American populations. Arch Dermatol, 81:95-102. 
